\title{
Pediatric parotideomasseteric pilomatrixoma in children
}

\author{
Richard Salzmana, Ivo Stareka , Hitari Faisala, Tomas Tichy ${ }^{b}$
}

\begin{abstract}
Aims. To review definitive histological diagnoses of patients with great salivary gland tumors with focus on the relatively high incidence of pediatric pilomatrixomas. The authors focus on clinical investigation, imaging methods and fine needle aspiration cytology of pilomatrixomas.

Methods. We treated 12 children with great salivary gland masses aged from 6 months to 18 years from 1995 to 2010 . The records of these patients were reviewed to determine sex, age, clinical presentation, and histological findings.

Results. Among children having true neoplasms, there was a prevalence of carcinomas (6 out of 9), with low-grade mucoepidermoid and acinic cell carcinomas (two each) as the dominating histopathological diagnosis. There was one adenoid cystic carcinoma and one curious undifferentiated carcinoma in a 6 month old baby. Among all 6 benign lesions, accounting for a half of the total, pilomatrixoma was the most common ( 2 out of 6 ) diagnosis, representing $17 \%$ (2 out of 12) of all salivary gland lumps and $66 \%$ (2 out of 3 ) of all true benign neoplasms.

Conclusions. Pilomatrixoma should be included in the differential diagnosis of pediatric parotideomasseteric lumps. Clinical investigation reveals adherence to the skin but not to the underlying tissue. Clinical assessment and ultrasound guided fine needle aspiration cytology in typical findings strongly support the diagnosis. Cytopathologists must be aware of the preliminary diagnosis of a pilomatrixoma to use proper fixation of the smears. In doubts, frozen biopsy must be sent before parotidectomy is performed.
\end{abstract}

Key words: pilomatrixoma, benign neoplasms, parotid neoplasms, differential diagnosis

Received: March 4, 2013; Accepted with revision: August 22, 2013; Available online: September 27, 2013 http://dx.doi.org/10.5507/bp.2013.063

${ }^{a}$ Department of Otorhinolaryngology, University Hospital Olomouc and Faculty of Medicine and Dentistry, Palacky University Olomouc, Czech Republic

${ }^{b}$ Department of Patholology, University Hospital Olomouc and Faculty of Medicine and Dentistry, Palacky University Olomouc Corresponding author: Richard Salzman, e-mail: richard.salzman@fnol.cz

\section{INTRODUCTION}

Salivary gland tumors in children account for no more than $5 \%$ of all cases of this oncological group ${ }^{1,2}$. Albeit showing a similarly high $80 \%$ parotid prevalence, they differ from those affecting adult populations primarily in their histopathological spectrum, with lymph- and hemangiomas being the most frequent entities ${ }^{3}$. Another striking differentiating feature is the rarity of pediatric salivary epithelial tumors, They represent only $3 \%$ of all pediatric salivary tumors ${ }^{4,5}$. However, up to $57 \%$ of them are histologically identified as carcinomas ${ }^{2,6}$. This is in stark contrast to absolute predominance of benign parotid tumors in adults.

Consequently, in the histopathologic spectrum of parotid lumps in childhood prevail other neoplastic, inflammatory and pseudotumorous affections, demanding usually less radical or even no surgery at all. One of the neoplasms that has to be taken into differential diagnostic considerations in pediatric parotid tumors is a pilomatrixoma, known for great difficulties in its preoperative diagnosis. This benign lesion, for the treatment of which a simple dissection preferably with up to $2 \mathrm{~cm}$ margins is recommended ${ }^{7}$, mimics many other conditions, including a salivary carcinoma. Such a misdiagnosed child might be, thus, overtreated with parotidectomy bearing potential adverse surgical consequences.
In our article, we, therefore, present tips and pitfalls of preoperative diagnostics of parotideomasseteric pilomatrixoma, based on relevant literature review as well as on our own experience. We focus on clinical investigation, imaging methods and fine needle aspiration cytology (FNAC).

\section{MATERIALS AND METHODS}

At our institution, a total of 540 patients with a lump in a great salivary gland were treated from 1995 to 2010, including $12(2.2 \%)$ children aged from 6 months to 18 years. The records of these pediatric patients were reviewed to determine sex, age, clinical presentation, and histological findings.

\section{RESULTS}

Three hundred eighty one (70\%) patients were diagnosed with a benign adenoma, $84(16 \%)$ with primary and $28(5 \%)$ with metastatic carcinoma, 21 (4\%) with malignant lymphoma, 20 (4\%) with pseudotumors, and 6 (1\%) with non-epithelial tumors. The histopathological diagnosis and location of lesions of the pediatric group are summarized in Table 1. Two children had reactive 
lymph node and pseudotumor each. There was one case of a huge lymphangioma, largely infiltrating head and neck soft tissues. Among those having true neoplasms, there was prevalence of carcinomas ( 6 out of 9 , i.e. $66.7 \%$ ), with low-grade mucoepidermoid and acinic cell carcinomas (two each) as dominating histopathological diagnosis. There was one adenoid cystic carcinoma and one curious undifferentiated carcinoma in a 6 months old baby. In our series, among all 6 benign lesions, accounting for a half of the total, pilomatrixoma was the most common (2 out of 6 , i.e. $33.3 \%$ ), ) diagnosis, representing 2 , i.e. $16.7 \%$, out of 12 salivary gland lumps and 2, i.e. $66.7 \%$, out of all 3 true benign neoplasms (lymphangioma excluded).

\section{DISCUSSION}

Pilomatrixoma (pilomatricoma, calcifying epithelioma of Malherbe) is a benign skin tumor, originating from hair matrix cells. This relatively common neoplasm accounts for one of every 500 specimens submitted by dermatologists $^{8}$. In about a half of all cases the tumor affects head and neck, with up to $40 \%$ preponderation of parotideomasseteric region ${ }^{9}$. Only $3 \%$ to $9.5 \%$ of head pilomatrixomas are located on the scalp ${ }^{10,11}$. The histopathological spectrum of pediatric salivary carcinomas in our cohort agrees with those published by other authors ${ }^{1,2,6}$. In their series of 43 pediatric solid salivary gland lesions, Bentz et al. ${ }^{3}$ reported a similar high frequency of pilomatrixomas. They represented $27.9 \%$ of benign and $20.9 \%$ of all histopathological entities.

Pilomatrixomas may appear at any age, with a bimodal peak in the first and sixth decade. Over $50 \%$ of all these tumors are diagnosed in pediatric population, with the majority (up to $88 \%$ ) of which occurring before 10 years of age ${ }^{11}$. A general slight prevalence in females increases (up to $70 \%$ ) under the age of 20 years $^{9,10}$. The average size of tumors varies around $1 \mathrm{~cm}^{9}$, but also large ones were described $^{12-14}$. Multiplicity is rare, not exceeding 3\% (ref. ${ }^{9}$ ). Pilomatroximas usually grow slowly, but rapid progression is also possible ${ }^{15}$.

Histopathologically, pilomatrixoma consists of eosinophilic keratinized (ghost) cells, sheet and bands of basaloid cells (Fig. 1). Typical is the presence of calcifications in ghost cell and ossifications in stromal region, that were found in $84 \%$ and $20 \%$, respectively, of 240 tumors studied by Forbis ${ }^{16}$. However, in another study, their somewhat lower occurence was reported ${ }^{11}$.

Upon palpation, pilomatrixoma usually presents as a stony hard mass ${ }^{15}$. In about $35 \%$ of all cases it is associated with pain and tenderness ${ }^{11}$, thus simulating malignancy. Approximately $80 \%$ of them are placed superficially, fixed to or rarely even ulcerating through the skin. They are distinguishable from infiltratively growing parotid carcinomas in that they are freely mobile against underlying gland parenchyma. The gross appearance of these pilomatrixomas rather varies, closely resembling skin squamous or basal cell carcinoma, malignant melanoma and haemangioma $^{10}$. Given the extraordinary rarity of the former three entities in children, practically the only lesion coming into the differential diagnostic considerations is haemangioma that may be easily diagnosed using ultrasound. Less common deep subcutaneously positioned pilomatrixomas are unapparent, but palpable with the presence of a tent sign, where stretching the overlying skin allows us to feel the irregular, multifaceted surface of the mass ${ }^{17}$. Such diversity in clinical appearance in combination with its low incidence explains the reported low rate of correct clinical preoperative diagnosis, varying from $21 \%$ (ref. $^{10}$ ) to $49 \%$ (ref. $^{9}$ ). In a series of 346 mostly pediatric pilomatrixomas $^{11}$, the diagnosis in $28.3 \%$ of all cases preoperatively remained unclear, while $6.9 \%$, respectively $8.7 \%$, were erroneously identified as dermoid cysts, respectively sebaceous cysts.

Given the difficulties in clinical preoperative diagnosis, imaging methods are used in preoperative assessment of pilomatrixomas.

If present, calcifications and ossifications can be, dependent on their size (ranging from microscopic through sand-like to gross), demonstrated on plain radiography ${ }^{18}$. With the advent of computerized imaging techniques, that method has fallen out in the preoperative diagnostics of soft tissue tumors. Recently the non-invasive, costeffective ultrasound (US) is generally preferred, showing a well circumscribed hyperechoic mass with tiny dense spots with acoustic shadowing ${ }^{19}$, caused by calcifications. Hughes $^{20}$ demonstrated that such characteristic US image correctly supported the clinical diagnosis of pilomatrixoma in the majority of 28 children with the suspicion of having that tumor.

Despite the fact, that pilomatrixoma is a relatively common affection; its MRI characteristics have not been studied extensively so far. In one reported case ${ }^{19}$, MRI revealed homogenous non-enhancing well-delineated mass, with small, calcification-related inhomogeneities. The signal intensity in T1-weighed and T2-weighed images was intermediate and low, respectively. The latter trait was thought to result from large amount of collagen within the tumor stroma. In pilomatrixoma one potentially pathognomonic feature, present on T2-weighed fat-suppressed images, was suggested by Hoffmann ${ }^{21}$, namely hypersignal bands radiating from the tumor center to its contrast enhancing periphery, related to basaloid cells.

Som reported that the CT scan showing a well circumscribed lesions with calcifications does not (in comparison with US) provide any additional conclusive information to that obtained from the US scan, and is, therefore, considered of limited use in the preoperative diagnostics of pilomatrixoma ${ }^{22}$.

Calcifications and ossifications in pilomatrixomas show strong multiplicity. This is an important feature distinguishing them from other, infrequently, rarely or even practically not occuring pediatric tumors (pleomorphic adenoma, adenoid cystic, carcinoma ex pleomorphic adenoma, other carcinomas, soft tissue and nerve sheet tumors, etc.), on the US or CT scans of which only single or at least a low number of calcifications are present.

In one of our two pilomatrixomas, numerous tiny hyperechoic spots were seen in the US image (Fig. 2). However, in that case the pathologist failed to find any 


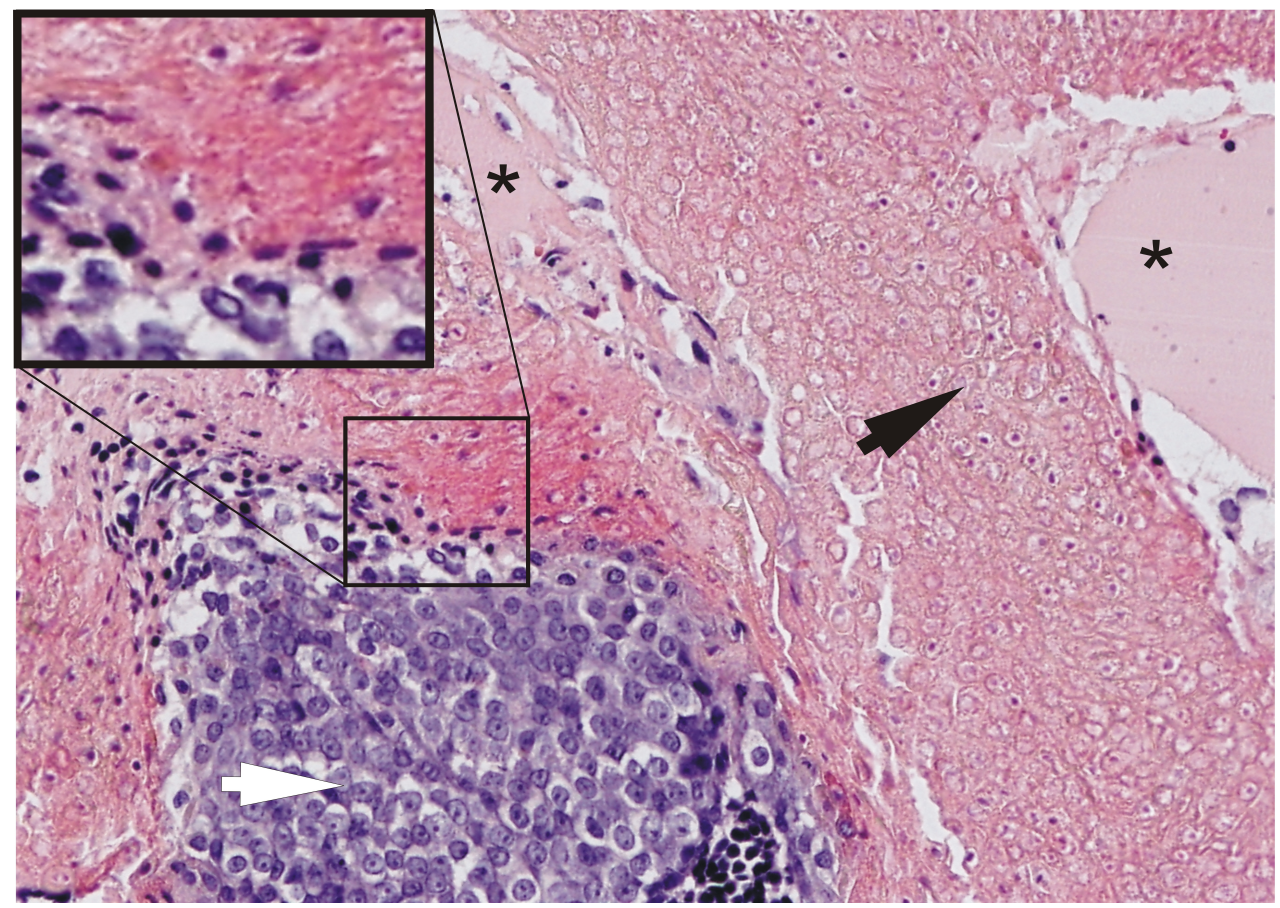

Fig. 1. Microphotograph of a pilomatrixoma. Bands of nucleated basaloid cells (white arrow) with scant cytoplasm exhibit deeply staining basophilic bland nuclei with occasional mitoses. Pale oesinophilic ghost (shadow) cells (black arrow) show distinct borders and central unstained area. Sporadically shrinked nuclei are present. Asterisks indicate foci of hyalinization. Inset: Basaloid cells undergoing apoptotic transition into ghost cells.

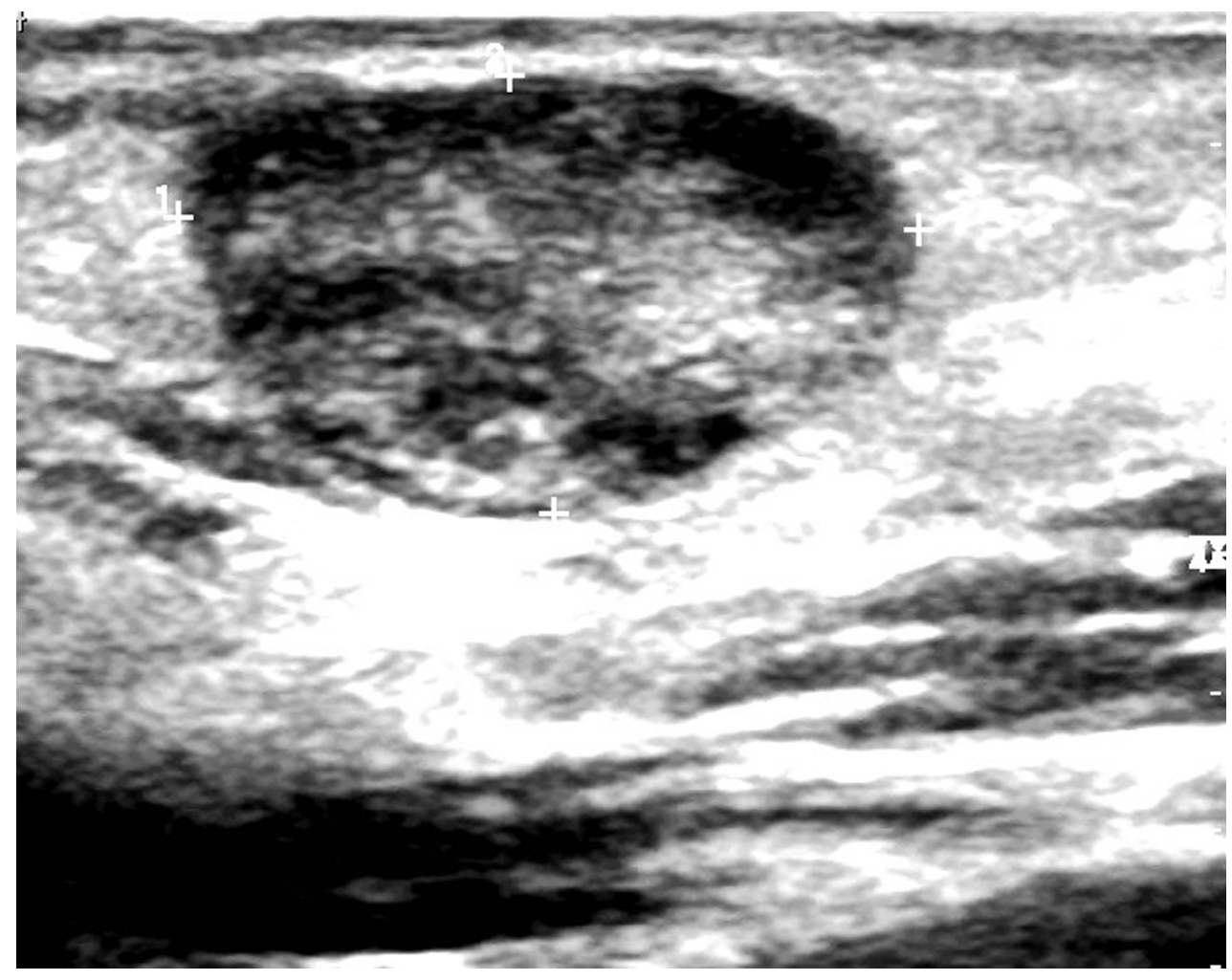

Fig. 2. Ultrasound scan reveals a well-delineated mass with numerous tiny hyperechoic spots. 
calcifications or ossifications. Instead, many fibrosed hyalinized patches were dispersed in ghost cell areas (Fig. 1), obviously responsible for the formation of those hyperechoic spots.

Very limited experience with PET/CT in pilomatrixoma was reported by Jung ${ }^{23}$, describing one case with F-18-G 'FDG uptake. The reason for the uptake remains unclear. We only hypothesize that PET positivity in pilomatrixomas might be caused by expression of glucose transporter 1 (GLUT1) as seen in some benign tumors, e.g. pleomorphic adenomas by Horiuchi ${ }^{24}$.

Owing to lack of any greater clinical experience with PET/CT in pilomatrixoma, that method can hardly be considered contributable in its preoperative differential diagnosis. Moreover, because of its potential uptake, the tumor might be over diagnosed as a carcinoma.

Another, albeit not generally accepted tool in preoperative diagnostic work-up of parotid lumps is fine needle aspiration cytology (FNAC). While the precise cytomorphologic characteristics of the most frequently occurring salivary adenomas and carcinomas were described by many cytopathologists, those of pilomatrixoma were not paid much attention until 1997, when Domanski ${ }^{25}$ defined reliable criteria for its cytomorphological diagnosis. This is based on the presence of two distinct cell populations, namely in clusters arranged as basaloid and anucleated shadow (ghost) cells as well as of calcium deposits. The coincidence of all these three features is pathognomonic for a pilomatrixoma, making other cytopathological diagnoses improbable. Giant and inflammatory cells and cell debris are very common additional findings in the aspirates.

In smears where the ghost cells, representing the key to recognizing a pilomatrixoma are not present, cytological findings may be misinterpreted. This is mainly due

Table 1. Pediatric solid salivary gland affections treated at our institution between 1995-2010.

\begin{tabular}{lcl}
\hline & $\begin{array}{c}\text { No (\%) of } \\
\text { patients }\end{array}$ & Location \\
\hline Benign & $\mathbf{6 ( 5 0 )}$ & \\
lymphangioma & $1(8)$ & parotid \\
pleomorphic adenoma & $1(8)$ & parotid \\
reparative granuloma & $1(8)$ & parotid \\
cat scratch disease & $1(8)$ & parotid \\
pilomatrixoma & $2(17)$ & parotid \\
\hline Malignant & $\mathbf{6 ( 5 0 )}$ & \\
undifferentiated & $1(8)$ & parotid \\
carcinoma & & \\
adenoid cystic & $1(8)$ & submandibular \\
carcinoma & & \\
mucoepidermoid & $2(17)$ & parotid \\
carcinoma & & \\
acinic cell & $2(17)$ & parotid \\
carcinoma & & \\
\hline
\end{tabular}

to the fact that some cytological features of a pilomatrixoma basaloid cells, such as high cellularity, nuclear hyperchromasia and background with cell debris closely remind those of high-grade squamous, small cell or basal cell salivary carcinomas. However, these entities, as well as other high-grade tumors occur extremely rarely in children. In the cytological differential diagnosis of the above mentioned affections bland nuclear characteristics in pilomatrixoma may be helpful ${ }^{26}$.

The most common pediatric salivary carcinomas that must be taken into cytologic differential diagnostic considerations of pilomatrixoma, are acinic cell and mucoepidermoid carcinomas, in this age category present almost always as low-grade lesions. The absence of basaloid cell in as well as specific cytological features of these two entities (acinar cells in the former and mucusproducing cells in the latter) confound the diagnosis of a pilomatrixoma. Other salivary gland tumors composed of basaloid cells, primarily adenoid cystic carcinoma must be distinguished. This is extremely necessary because of its infiltrative growth, requiring total parotidectomy. In cribriform variety showing the presence of typical globules, the cytological differential diagnosis is not difficult. However, it is not true for trabecular and especially highly aggressive solid adenoid cystic carcinoma, lacking these globules.

As demonstrated by Domanski ${ }^{25}$, the presence of ghost cells in cytological aspirates from pilomatrixomas is rare in alcohol-fixed and abundant in air-dried smears. Consequently, clinicians should make the cytopathologist alert to the potential diagnosis of a pilomatrixoma.

Pilomatrixoma presents a very important item in the differential diagnosis of pediatric parotideomasseteric lumps. Clinical investigation is cardinal, with the tent sign or adherence to the skin but not to the underlying tissue being a crucial marker, allowing us to distinguish pilomatrixoma from salivary gland carcinoma. Clinical suspicion of a pilomatrixoma is strongly supported by US which shows a well-delineated mass with multiple calcifications. CT is not useful if US is performed. The role of MRI in preoperative diagnosis of pilomatrixoma is not clear, deserving further investigation. The same is true for PET/CT, in which the uptake mimics malignancy. Clinical assessment and US should be completed by FNAC, which in typical findings strongly supports the diagnosis. Cytopathologist must be aware of the preliminary diagnosis of a pilomatrixoma to use proper fixation of the smears. In doubts, frozen biopsy must be performed before parotidectomy is performed.

\section{ACKNOWLEDGEMENT}

The authors thank Mr. George Kumsta for the English review during preparation of the manuscript.

Authorship contributions: RS, IS: literature search, manuscript writing, HF: surgeon, TT: histological examination, IS: final approval.

Conflict of interest statement: None declared. 


\section{REFERENCES}

1. Schuller DE, McCabe BF. The firm salivary mass in children. Laryngoscope 1977;87(11):1891-8.

2. Jacques DA, Krolls SO, Chambers RG. Parotid tumors in children. Am J Surg 1976;132(4):469-71.

3. Bentz BG, Hughes CA, Lüdemann JP, Maddalozzo J. Masses of the Salivary Gland Region in Children. Arch Otolaryngol Head Neck Surg 2000;126(12):1435-9.

4. Callender DL, Frankenthaler RB, Luna MA, Lee S, Goepfert M. Salivary gland neoplasms in children. Arch Otolaryngol Head Neck Surg 1992;118:472-6.

5. Luna AM, Batsakis, JG, El-Naggar AK. Salivary gland tumors in children. Ann Otol Rhinol Laryngol 1991;100:869-71.

6. Chong GC, Beahrs OH, Chen ML, Hayles AB. Management of parotid gland tumors in infants and children. Mayo Clin Proc 1975;50(5):27983 .

7. Strobl H, Emshoff R. Pilomatrixoma of the cheek: Report of a case. J Oral Maxillofac Surg 1995;53:1355-7.

8. Marrogi AJ, Wick MR, Dehner LP. Pilomatrical neoplasms in children and young adults. Am J Dermatopathol 1992;14(2):87-94.

9. Danielson-Cohen A, Lin SJ, Hughes CA, Maddalozzo J. Head and neck pilomatrixoma in children. Arch Otolaryngol Head Neck Surg 2001;127:1481-3.

10. Julian C, Bowers PW. A clinical review of 209 pilomatrixomas. J Am Acad Dermatol 1998;39:191-5.

11. Pirouzmanesh AB, Reinish JF, Gonzales-Gomez I, Smith E, Meara JG. Pilomatrixoma: a review of 346 cases. Plast Reconst Surg 2003;112:1784-9.

12. Cozzi DA, d'Ambrosio G, Cirigliano E, Negro V, lacusso Ch, Totonelli G Uccini S. Giant pilomatricoma mimicking a malignant parotid mass. J Ped Surg 2011;46:1855-8

13. Fernandez R, Holmes J, Mullenix C. Giant pilomatricoma (epithelioma of Melherbe): report of a case and review of literature. J Oral Maxillofac Surg 2003;61:634-6.
14. Kovacic M, Rudic M, Nekic I, Lisica-Sikic N, Kranjec Z, Simurina T. Giant pilomatrixoma (benign calcifying epithelioma of Malherbe) of the neck and face. Dermatol Surg 2007;33:340-3.

15. Tsoitis G, Mandinaos C, Kanitakis JC. Perforating calcifying epithelioma Malherbe with a rapid evolution. Dermatologica 1984;168(5):233-7.

16. Forbis R, Helwig EG. Pilomatrixoma (calcifying epithelioma). Arch Dermatol 1961;83:606-18.

17. Graham JL, Merwin CF. The tent sign of pilomatricoma. Cutis 1978:22(5):577-80.

18. Haller JO, Kassner EG, Ostrowitz A, Kottmeler K, Perfschuk LP. Pilomatrixoma (calcifying epithelioma of Malherbe): radiographic features. Radiology 1977;123(1):151-3.

19. De Beuckeleer LH, De Schepper AM, Neetens I. Magnetic resonance imaging of pilomatricoma. Eur Radiol 1996;6:72-5.

20. Hughes J, Lam A, Rogers M. Use of ultrasonographyx in the diagnosis of childhood pilomatrixoma. Pediatr Dermatol 1999;16(5):341-4.

21. Hoffmann V, Roeren T, Möller P, Heuschen G. MR imaging of pilomatrixoma. Pediatr Radiol 1998;28(4):272.

22. Som, PM, Shugar JM, Silvers AR. CT of pilomatrixoma in the cheek. Am J Neuroradiol 1998;19(7):1219-1220.

23. Jung Y, Kang JG, Park WS, Ryu J. Pilomatricoma: Diagnostic pitfalls in PET/CT and fine-needle aspiration biopsy. Otolaryngol Head Neck Surg 2007; 137:845-6.

24. Horiuchi C, Tsukuda M, Tagichu T, Ishiguro Y, Okudera $K$, Inoue T. Correlation between FDG-PET findings and GLUT1 expression in salivary gland pleomorphic adenomas. Ann Nucl Med 2008;22(8):693-8.

25. Domanski HA, Domanski AM. Cytology of pilomatrixoma (calcifying epithelioma of Malherbe) in fine needlel aspiration. Acta Cytol 1997:41(3):771-7.

26. Solanki P, Ramzy I, Durr N, Henkes D. Pilomatrixoma. Cytologic features with differential diagnostic considerations. Arch Pathol Lab Med 1987;111(3):294-7 